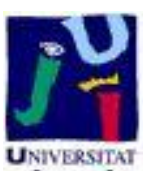

Título artículo / Títol article: Electrodeposited $\mathrm{NiO}$ anode interlayers: Enhancement of the charge carrier selectivity in organic solar cells

Autores / Autors

Ripollés Sanchis, Teresa ; Guerrero Castillejo, Antonio ; Azaceta, Eneko ; Tena Zaera, Ramón ; Garcia Belmonte, Germà

Revista:

Solar Energy Materials and Solar Cells Volume 117, October 2013

Versión / Versió:

Preprint de l'autor

Cita bibliográfica / Cita bibliogràfica (ISO 690):
Ripolles-Sanchis, T., Guerrero, A., Azaceta, E., Tena-Zaera, R., \& Garcia-Belmonte, G. (2013). Electrodeposited $\mathrm{NiO}$ anode interlayers:

Enhancement of the charge carrier selectivity in organic solar cells. Solar Energy Materials and Solar Cells, 117, 564-568

url Repositori UJI: http://hdl.handle.net/10234/83909 


\title{
Electrodeposited $\mathrm{NiO}$ anode interlayers: Enhancement of the charge carrier selectivity in organic solar cells
}

\author{
Teresa Ripolles-Sanchis ${ }^{1}$, Antonio Guerrero ${ }^{1}$, Eneko Azaceta ${ }^{2}$, Ramon Tena-Zaera ${ }^{2, *}$, \\ and Germà Garcia-Belmonte ${ }^{1, *}$ \\ ${ }^{1}$ Photovoltaic and Optoelectronic Devices Group, Departament de Física, Universitat \\ Jaume I, ES-12071 Castelló, Spain \\ ${ }^{2}$ Energy Division, IK4-CIDETEC, ES-20009, San Sebastian, Spain
}

\begin{abstract}
Nickel oxide $(\mathrm{NiO})$ thin films prepared by cathodic electodeposition exhibit superior electrical performace than PEDOT:PSS when used as anode interlayers of bulkheterojunction solar cells. Devices incorporating $30 \mathrm{~nm}$-thick $\mathrm{NiO}$ films firstly annealed at $320^{\circ} \mathrm{C}$ in air and posteriorly treated with $\mathrm{UV}^{-\mathrm{O}_{3}}$ reach power conversion efficiencies comparable to that obtained for PEDOT:PSS-based cells. NiO interlayers enhance contact selectivity by simulataneously increasing shunt resistance (lower leakage current related to electron-blocking ability), and reducing hole-extraction resistance. Carrier selectivity is quantified from the resistance components associated with the impedance response of the anode contacts. The versatile electrodeposition technique of $\mathrm{NiO}$ interlayers permits avoiding PEDOT:PSS use as it presents disadvantages related to its acid character and hygroscopic nature.
\end{abstract}

Keywords: Organic photovoltaics, nickel oxide, hole transport layer, charge carrier selectivity.

*Corresponding authors: G. Garcia-Belmonte, e-mail: garciag@uji.es, tel.: +34 964 387538, and Ramon Tena-Zaera, e-mail: rtena@cidetec.es, tel: +34 943309022

Published in Solar Energy Materials \& Solar Cells 117(2013)564-568 


\section{Introduction}

The increasing demand for renewable energy resources leads researchers to study different routes in solar energy production. Nowadays, organic bulk heterojunction (BHJ) solar cells are deeply investigated due to their potential to reduce fabrication costs. This is so because mechanical flexibility, light weight and manufacturing using solution-based processing as spray coating or inkjet printing, which are appealing for roll-to-roll production, make the technology highly attractive.[1,2] Up to now the maximum power conversion efficiency (PCE) is on the order of $\sim 10 \%$ [3-7]. BHJ cells typically integrate blends formed by a donor polymer, such as poly (3-hexylthiophene) (P3HT) and an acceptor fullerene, such as [6,6]-phenyl-C61-butyric acid methyl ester $\left(\mathrm{PC}_{60} \mathrm{BM}\right)$. Efficient electrodes comprise a transparent conducting oxide (TCO) anode, such as indium tin oxide (ITO), and a low work function metal cathode. A hole transport layer (HTL) is deposited between the TCO anode and bulk heterojunction layer to enhance hole extraction by reducing contact resistance, acting simultaneously as an electron-blocking layer. The most commonly employed HTL material in polymer solar cell is the copolymer poly $(3,4-$ ethylenedioxythiophene):poly(styrenesulfonate) (PEDOT:PSS) [8], because it is insoluble in organic solvents, conductive, and highly transparent to visible light. However, PEDOT:PSS presents some disadvantages as their acid character $(\mathrm{pH}=1.2)$ and hygroscopic nature cause corrosion of the ITO anode subsequently allowing indium diffusion throughout the device [9]. Other alternatives for an efficient anode interlayer material could be wide band gap $\left(E_{g} \geq 3 \mathrm{eV}\right)$ p-doped materials such as several transition metal oxides $\left(\mathrm{V}_{2} \mathrm{O}_{5}, \mathrm{MoO}_{3}\right.$, and $\left.\mathrm{WO}_{3}\right)$ [10-13] which are usually incorporated using less convenient vacuum deposition techniques. Therefore it would be necessary to investigate on HTL materials processed from solution routes. An ideal candidate can be nickel oxide (NiO). However it is known that $\mathrm{NiO}$ contact properties are highly sensitive to the surface chemistry, crystal orientation and thin film processing [7]'[14, 15].

In this work, an efficient anode $\mathrm{NiO}$ interlayer is prepared on top of the ITO by a versatile cathodic electrochemical deposition method [16]. Surface treatments such as UVozone (UVO) and annealing treatment (AT) in air allows reducing contact resistance and simultaneously increasing shunt resistance, enhancing as a consequence photovoltaic parameters. In particular carrier selectivity of the anodes is quantified from the resistance components associated with the impedance response of the contacts. Compared to the PEDOT:PSS HTL, solar cells including NiO exhibit superior electrical characteristics 
(carrier selectivity $s>99 \%$ ).

\section{Results and discussion}

Two different HTLs were tested: namely PEDOT:PSS layers, and $\mathrm{NiO}$ films. PEDOT:PSS was spin coast onto ITO-coated glass substrate $(10 \mathrm{Ohm} / \mathrm{sq})$ at $5500 \mathrm{rpm}$ for $30 \mathrm{~s}$, then $3000 \mathrm{rpm}$ for $30 \mathrm{~s}$ in air. The thickness of the PEDOT:PSS layer was about 30 $\mathrm{nm}$, as determined by a VEECO DEKTACK 6M Stylus Profiler. To remove the traces of water, the substrates were heated at $130{ }^{\circ} \mathrm{C}$ for $10 \mathrm{~min}$. $\mathrm{NiO}$ deposition on the ITO was performed from the electrochemical reduction of $\mathrm{O}_{2}$ in an aprotic ionic liquid (i.e. 1-butyl1-methylpyrrolidinium bis(trifluoromethanesulfonyl)imide, PYR ${ }_{14} \mathrm{TFSI}$ )-based electrolyte containing nickel bis(trifluoromethanesulfonyl)imide $\left(5 \times 10^{-2} \mathrm{M}\right)$. Further experimental details can be found elsewhere.[16] Charges densities of 13 and $25 \mathrm{mC} / \mathrm{cm}^{2}$ were passed during the electrodeposition in order to obtain $\mathrm{NiO}$ films with thickness of 30 and $50 \mathrm{~nm}$, respectively. Some of the obtained $\mathrm{NiO}$ samples were heated at $320{ }^{\circ} \mathrm{C}$ for $20 \mathrm{~min}$ (annealing treatment AT), and then UVO treatment were carried on for $10 \mathrm{~min}$. Other 30 nm-thick NiO films were analyzed reversing the processing: firstly UVO treatment was performed and then submitted to AT with the same conditions as in the previous devices. Also $30 \mathrm{~nm}$-thick NiO films were studied as-deposited without any post-treatments. The active layer consisting of $\mathrm{P} 3 \mathrm{HT}$ and $\mathrm{PC}_{60} \mathrm{BM}$ blend was spin-cast in a glove box from orthodichlorobenzene (ODCB) solution on top of the HTL layer. The active layer was deposited at $1200 \mathrm{rpm}$ for $10 \mathrm{~s}$ (100 nm-thick). The films were then annealed on a hot plate in the glove box at $130{ }^{\circ} \mathrm{C}$ for $10 \mathrm{~min} . \mathrm{Ca} / \mathrm{Ag}(5 \mathrm{~nm} / 100 \mathrm{~nm})$ cathodes were used as top electrodes by thermal evaporation. Devices of structure glass/ITO/HTL/P3HT:PC ${ }_{60} \mathrm{BM} / \mathrm{Ca} / \mathrm{Ag}$ are analyzed by impedance spectroscopy (IS) technique under 1 sun illumination.

The morphology of $\mathrm{NiO}$ layers is analyzed by scanning electron microscopy. Although conformal-like $\sim 30 \mathrm{~nm}$ thick coating of the ITO substrate is observed after electrodeposition experiments passing a charge density of $13 \mathrm{mC} / \mathrm{cm}^{2}$ (Figures $1 \mathrm{~b}$ and $\mathrm{d}$ ), a decrease of roughness -versus to the naked substrates (Figure 1a)- can be inferred in samples obtained after applying $25 \mathrm{C} / \mathrm{cm}^{2}$ (Figure 1c). The decrease of the roughness for thicker layers was confirmed by atomic force microscopy [16]. The substrates coated with the different HTLs are characterized UV-Vis spectra (Figure 2), detecting significant changes in the transmittance of the $\mathrm{NiO}$ films as-deposited and after each treatment. The 
differences suggest changes in the $\mathrm{NiO}$ stoichiometry. It is observed a similar high transmittance for the as-deposited and after UVO/AT treatments of $30 \mathrm{~nm}$-thick $\mathrm{NiO}$ films and PEDOT:PSS film. Transmittance lowers when AT/UVO is performed on NiO films with different thicknesses 30 and $50 \mathrm{~nm}$. This transmittance reduction is reflected in the photovoltaic characteristics as discussed later. Previous research informs that the work function of $\mathrm{NiO}$ is strongly dependent on the thickness, $\mathrm{O}_{2}$-plasma, and annealing treatments [17]. For example, a $\mathrm{O}_{2}$-plasma treatment increases the work function of $\mathrm{NiO}$, by forming $\mathrm{NiO}_{x}$ layers with their electronic properties dictated by the formation of metal cation vacancies, and regions in the oxide lattice which are rich in oxygen [17]. Also deposition methods such as pulsed laser deposition, sol-gel route, or sputtering play a determining influence $[9,18]$. We consider here that UVO treatment followed in our experiments produces similar effects as those occurring after $\mathrm{O}_{2}$-plasma treatment [18]. Furthermore, recent research reveals that ozone exposure increased the Ni oxidation state by introducing hole states, giving rise to higher-performance aluminum-coated $\mathrm{NiO}$ films [19].

The electrical properties of the glass/ITO/HTL/P3HT:PC ${ }_{60} \mathrm{BM} / \mathrm{Ca} / \mathrm{Ag}$ solar cells are shown as current density-voltage $j-V$ characteristics under simulated AM1.5G illumination $\left(1000 \mathrm{~W} \mathrm{~m}^{-2}\right.$ ) (Figure 3a). The photovoltaic parameters for PEDOT:PSS and all NiO interlayer-based devices are summarized in Table 1 . It is clearly observed that the $\mathrm{NiO}$ as-deposited device has the lowest photovoltaic parameters (see Table 1) indicating that surface treatments are necessary to improve contact conditions. When $\mathrm{NiO}$ films are annealing before UVO treatment, the open-circuit voltage yields $\sim 620 \mathrm{mV}$ (see Table 1), a value similar to that achieved with PEDOT:PSS. However $30 \mathrm{~nm}$-thick NiO-based device with firstly UVO treatment (UVO/AT) only yields $260 \mathrm{mV}$ (see Table 1). This last observation suggests that the $\mathrm{NiO}$ film with the previous UVO treatment exhibits blocking characteristics as next explaining in describing impedance spectroscopy results. The optimum interlayer observed in the photovoltaic results corresponds to the $30 \mathrm{~nm}$-thick $\mathrm{NiO}$ when UVO treatment is done after annealing. This results in an power conversion efficiency of $3.44 \%$, comparable to a common device with PEDOT:PSS. The main difference between these two cells is the short-circuit current $j_{\mathrm{sc}}$ and EQE response (Figure $3 \mathrm{~b}$ ). The lower $j_{\mathrm{sc}}$ for the $30 \mathrm{~nm}$-thick NiO (AT/UVO) solar cell is attributed to the lower transmittance spectra as observed in Figure 1. However NiO-based cell exhibits an improved fill factor (FF) in comparison to PEDOT:PSS-based cell (see Table 1). FF is 
kwon to be connected to resistive effects, either in series or in parallel, which limits the electrical power delivered by solar cell. Improvement in contact resistive effects derives from the capacity of the outer anode interface for simultaneous (i) hole extraction and (ii) electron blocking, a feature that states the contact selectivity [20]. We next use impedance spectroscopy to discern out the origin of such FF increment.

Impedance spectroscopy (IS) is an experimental technique able to separate different resistive and capacitance contributions to the overall solar cell electrical response [21]. NiO-based devices and a standard device with PEDOT:PSS as HTL are studied by IS under 1 sun irradiation intensity by varying bias voltage. $Z^{\prime}-Z^{\prime \prime}$ plots exhibit a typical impedance response of organic solar cells displaying two arcs (see Figure 3) [22, 23]. The equivalent circuit model shown in Figure 4 provides a high quality fit of the data for all devices. At lower frequencies, a large arc dominates in the $Z^{\prime}-Z^{\prime \prime}$ plot which is represented by a $R C$ subcircuit. This part is related to the recombination resistance $R_{\text {rec }}$, derivative of the carrier recombination flux; and the chemical capacitance $C_{\mu}$ related to carrier storage [21]. At higher frequencies, an additional arc is clearly observed in the $\mathrm{Z}^{\prime}-$ $\mathrm{Z}^{\prime \prime}$ plot for the $30 \mathrm{~nm}$-thick NiO (UVO/AT)-based solar cell (Figure 4). This highfrequency arc is also visible, although to a minor extent, with the other devices (shown in Figure 3 for $30 \mathrm{~nm}$-thick NiO (AT/UVO)-based device). This extra arc at high frequencies is represented by a parallel $R C$ which is directly dependent on the HTL/active layer interface. It is interpreted in terms of an interlayer resistance $R_{\mathrm{i}}$ and capacitance $C_{\mathrm{i}}$. The equivalent circuit model has also a series resistance $R_{\mathrm{s}}$ resulting from the electrode contacts.

IS parameters extracted from fitting of the Nyquist plots using the equivalent circuit model showed in Figure 4 are shown in Figure 5. NiO (UVO/AT)-based device show a voltage-independent, high $R_{\mathrm{i}} \sim 70 \Omega \mathrm{cm}^{2}$ (Figure 4a). This is a considerable resistance that contributes to hinder hole extraction at the anode contact. We had studied a similar blocking-like behavior with a $\mathrm{CaO}$ layer at the cathode [23]. Performing annealing treatment before UVO seems necessary to reduce the contact resistance. This is likely due to a better matching in the energy levels at the interface. Thicker NiO interlayers $(50 \mathrm{~nm}$ AT/UVO) exhibit intermediate $R_{\mathrm{i}}$ values $\left(\sim 30 \Omega \mathrm{cm}^{2}\right)$ in comparison to those obtained with thinner NiO (30 $\mathrm{nm} \mathrm{AT/UVO)} \mathrm{and} \mathrm{PEDOT:PSS}\left(<10 \Omega \mathrm{cm}^{2}\right)$. It is interesting to note that $R_{\mathrm{i}}$ for these last cells contributes similarly to the overall series resistance. However the 
thinner NiO-layer cell presents lower $R_{\mathrm{i}}$ values around the maximum power point. This explains in part the increment in FF exhibited by the NiO-based cell (see Table 1). Other possible factors influencing FF are originated by recombination currents (represented by $R_{\mathrm{rec}}$ ), and leakage current (modeled by the shunt resistance $R_{\mathrm{sh}}$ ) determining the slope of the $j-V$ curves near short circuit.

The recombination resistance $R_{\text {rec }}$ (Figure $5 \mathrm{~b}$ ) follows the expected decreasing behavior at forward voltage due to the enhancement of the recombination current [21]. At low voltages $R_{\text {rec }}$ tends to saturate because the differential resistance measured is not determined by the recombination flux but by a shunt resistance $R_{\mathrm{sh}}$ caused by additional leakage currents flowing in parallel [22]. In that region, $R_{\mathrm{sh}}$ corresponding to the $30 \mathrm{~nm}$ $\mathrm{NiO}$ (AT/UVO) solar cell is higher than that exhibited by others devices. This effect is reflected in the $j-V$ curve which has a nearly flat response at low voltages. At higher voltages, $R_{\text {rec }}$ shows similar decreasing behavior for the working devices (PEDOT:PSS and $30 \mathrm{~nm}$-thick $\mathrm{NiO}$ AT/UVO). This fact precludes connecting the differences in FF to recombination currents occurring within the active layer bulk. On the contrary large $R_{\mathrm{sh}}$ variations (from $\sim 200 \Omega \mathrm{cm}^{2}$ with PEDOT:PSS to $\sim 3 \mathrm{k} \Omega \mathrm{cm}^{2}$ with thin NiO AT/UVO) are directly linked with the increment in FF, which finally improves performance. The interplay between hole extraction (low $R_{\mathrm{i}}$ values) and leakage current blocking (high $R_{\mathrm{sh}}$ ) is used to define the carrier selectivity degree exhibited by the anode contact. We propose that the contact selectivity can simply be expressed as

$$
S=1-\frac{R_{\mathrm{i}}}{R_{\mathrm{sh}}}
$$

which results in $s=1$ for a fully selective contact. Selectivity values are summarized in Table 1. It is noted that $s$ correlates with FF as expected. The definition of contact selectivity in Eq. (1) tries to capture the balance between the charge (hole) extraction ability of the anode and the detrimental leakage current flowing in parallel to the photocurrent. The ratio between $R_{\mathrm{i}}$ and $R_{\mathrm{sh}}$ compares the anode opposition to the hole extraction in the energy-generating quadrant of the $j-V$ curve and the resistance caused by the leakage current.

The capacitance plot $C_{\mu}$ (Figure $5 \mathrm{~d}$ ) of the 30 nm-thick $\mathrm{NiO}$ (AT/UVO) and PEDOT:PSS-based devices exhibits at higher voltages the expected increase as fullerene states are occupied toward forward bias [21]. The $30 \mathrm{~nm}$-thick $\mathrm{NiO}$ (UVO/AT) cell shows 
a voltage-independent $C_{\mu}$ under illumination related to the blocking behavior which approximately corresponds to the chemical capacitance found for working cells at $V_{\text {app }} \approx 400 \mathrm{mV}$. A similar behavior was found when insulating layer were intentionally deposited at the cathode contact [23]. At lower voltages all devices exhibit the expected capacitive response originated by the modulation of the depletion zone built up at the cathode contact, which collapses to the geometrical capacitance near zero voltage [24]. Finally Figure $5 \mathrm{c}$ represents $C_{\mathrm{i}}$ versus applied voltage. The $30 \mathrm{~nm}$-thick NiO (AT/UVO) and PEDOT:PSS HTL-based OPV devices have the same behavior which increases toward forward bias. On the contrary the other devices exhibit almost constant, lower $C_{\mathrm{i}}$ values. The transition between low to high $C_{\mathrm{i}}$ appears to be connected to the change between dielectric to charge accumulation mechanisms at the interlayer.

\section{Conclusions}

We finally remark that $\mathrm{NiO}$ electrodeposition from aprotic ionic liquids appears to be a viable vacuum-free approach to integrate HTL in BHJ solar cells in a single-step process (i.e avoiding the post-deposition thermal treatments need in the aqueous-based electrodeposition [15], and the consequent traces of nickel hydroxide-related phases present even after annealing treatments [25]. Surface treatments such as UVO and annealing treatment have an important effect on the electrical behavior of the $\mathrm{NiO}$ as anode interlayer. Different thicknesses (30 and $50 \mathrm{~nm}$ ) and treatment order (AT/UVO or $\mathrm{UVO} / \mathrm{AT}$ ) have been studied in the conventional device architecture of organic solar cells. The efficiency values of the device prepared with $30 \mathrm{~nm}$-thick NiO film (AT/UVO) HTL is comparable with a standard PEDOT:PSS. NiO interlayers present a superior electrical response as evidenced by the reduction in the overall series resistance, and larger shunt resistance. These two parameters allow explaining the higher FF observed for $30 \mathrm{~nm}$-thick $\mathrm{NiO}$ AT/UVO films. The proposed analytical technique based on IS can be further used when different contact structures are compared, allowing for a quantification of the carrier selectivity.

\section{Acknowledgements}

We thank financial support from Ministerio de Educacion y Ciencia under Project 
HOPE CSD2007-00007 (Consolider-Ingenio 2010), Generalitat Valenciana (Prometeo/2009/058, and ISIC/2012/008 Institute of Nanotechnologies for Clean Energies), and FP7 European Project ORION (Large CP-IP229036-2). R.T-Z. acknowledges the support of the Program "Ramón y Cajal" of the MICINN. 


\section{Figure captions}

\section{Figure 1.}

Top view SEM micrographs of a naked ITO substrate (a) and NiO layers electrodeposited by passing a charge density of 13 (b) and $25 \mathrm{mC} / \mathrm{cm}^{2}$ (c). The figure d shows a cross section SEM micrograph of the sample showed in figure $b$.

\section{Figure 2}

Transmission spectra of HTL films ontop of ITO substrates. The HTL analyzed were PEDOT:PSS film and NiO films treated by the following ways: as-deposited $(30 \mathrm{~nm})$, AT/UVO (30 and $50 \mathrm{~nm})$ and UVO/AT (30 nm).

\section{Figure 3}

(a) Current density-voltage plots under 1 sun illumination for glass/ITO/HTL/P3HT:PC ${ }_{60} \mathrm{BM} / \mathrm{Ca} / \mathrm{Ag}$ BHJ solar cells fabricated with PEDOT:PSS (standard device) and $\mathrm{NiO}$ films (as-deposited, AT/UVO and UVO/AT for $30 \mathrm{~nm}$ thick and $50 \mathrm{~nm}$ thick for AT/UVO). (b) EQE spectra of glass/ITO/PEDOT:PSS or $30 \mathrm{~nm} \mathrm{NiO}$ (AT/UVO)/P3HT:PC ${ }_{60} \mathrm{BM} / \mathrm{Ca} / \mathrm{Ag}$ devices.

\section{Figure 4}

$Z^{\prime}-Z^{\prime \prime}$ plot of $30 \mathrm{~nm}$-thick NiO UVO/AT and AT/UVO-based solar cell at $300 \mathrm{mV}$ bias voltage under 1 sun illumination. The equivalent circuit model is also indicated, which comprises a series resistance $R_{\mathrm{S}}$, interlayer resistance $R_{\mathrm{i}}$, interlayer capacitance $C_{\mathrm{i}}$, recombination resistance $R_{\text {rec }}$, and chemical capacitance $C_{\mu}$.

\section{Figure 5}

(a) Interlayer resistance $R_{\mathrm{i}}$, (b) recombination resistance $R_{\mathrm{rec}}$, (c) interlayer capacitance $C_{\mathrm{i}}$, and (d) chemical capacitance $C_{\mu}$ as a function of the applied voltage extracted from the fitting of the equivalent circuit model shown in Figure 3. 


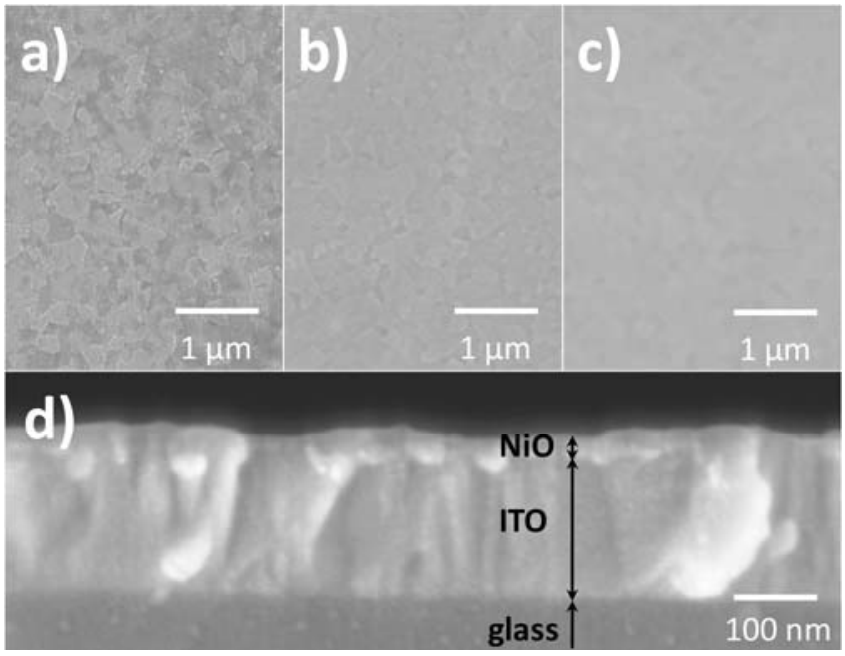

Figure 1

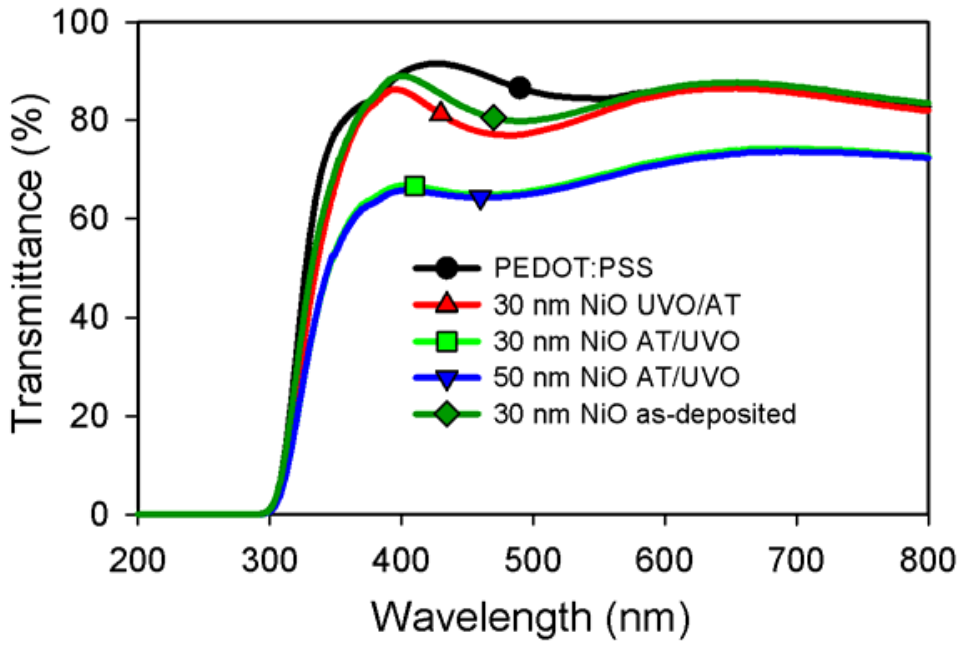

Figure 2 

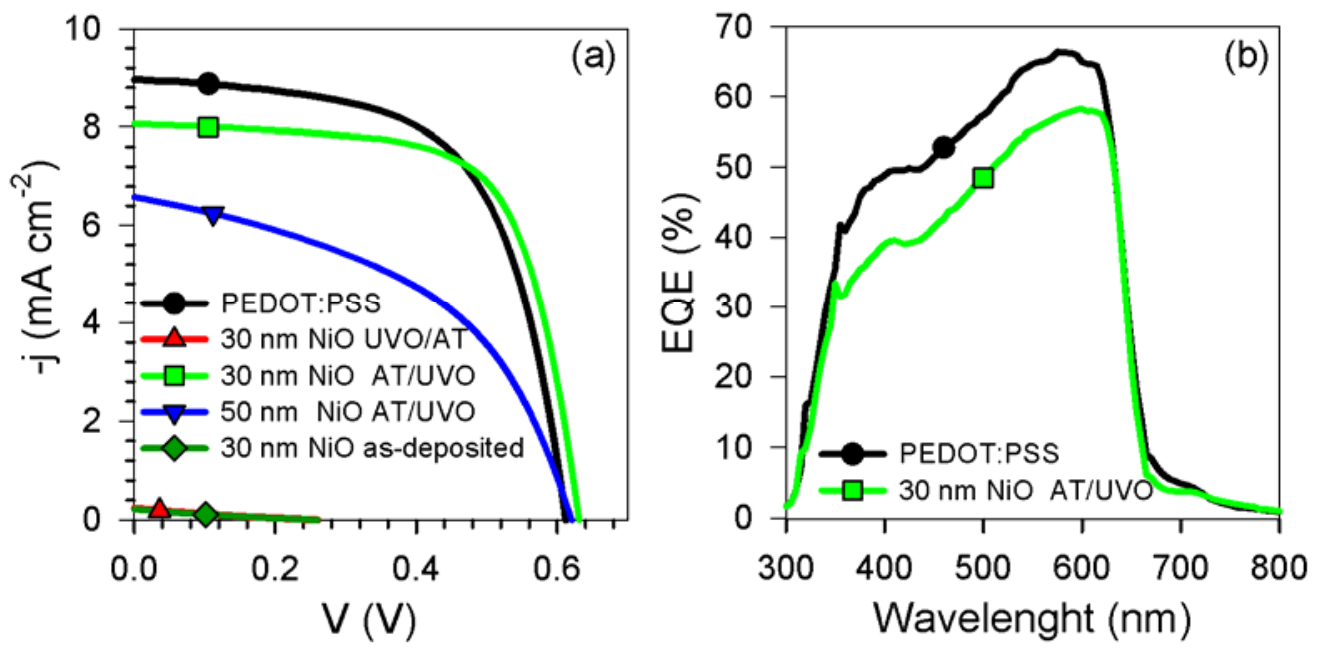

Figure 3

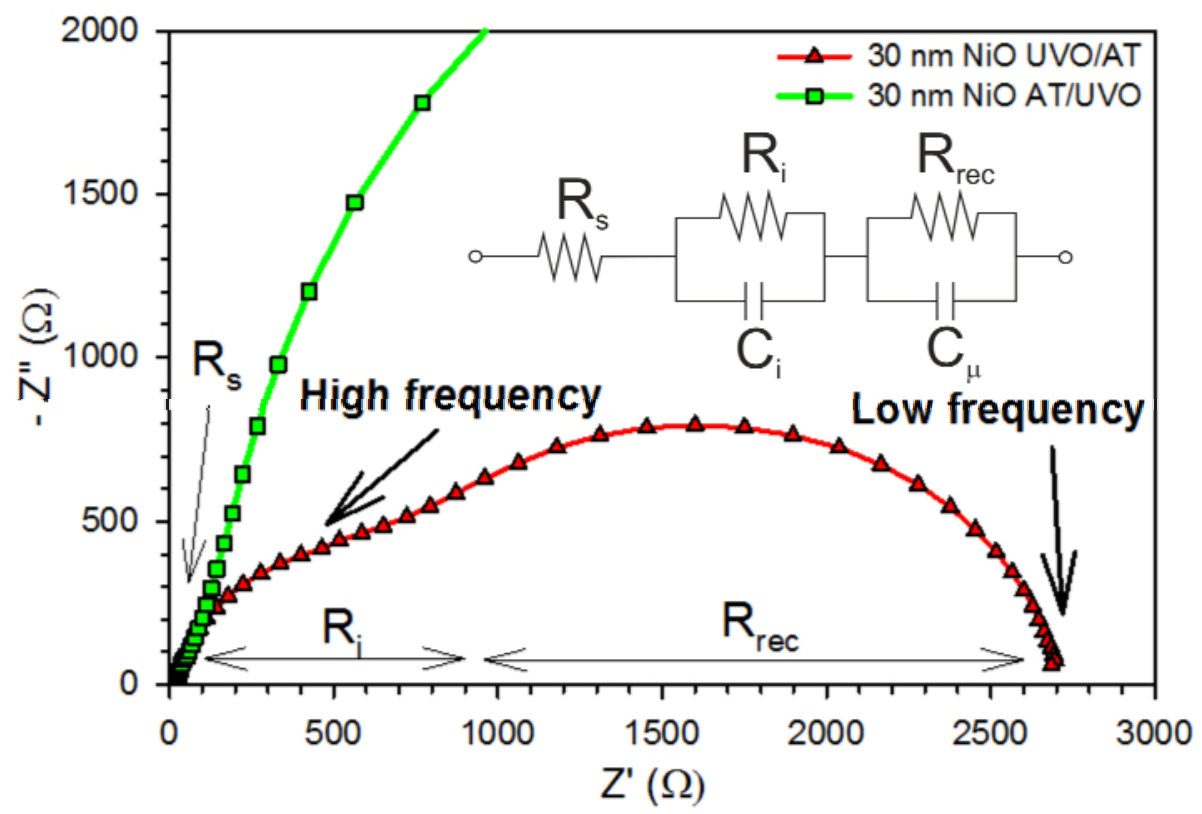

Figure 4 


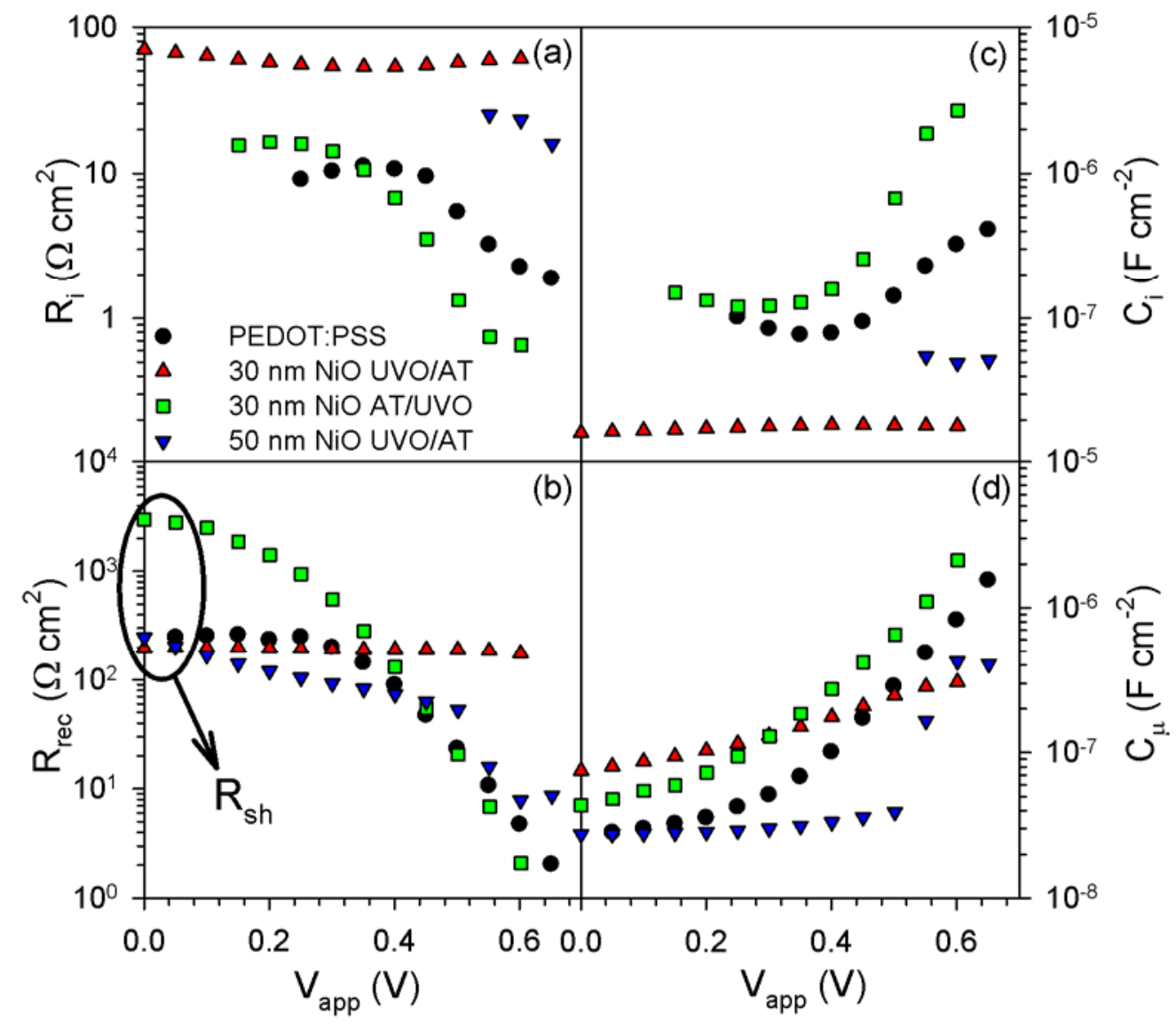

Figure 5

\section{Table 1}

Photovoltaic characteristics for $\mathrm{P} 3 \mathrm{HT}: \mathrm{PC}_{60} \mathrm{BM}$ solar cells with PEDOT:PSS and $\mathrm{NiO}$ interlayers. AT = annealing treatment.

\begin{tabular}{cccccccc}
\hline HTL & $\begin{array}{c}\text { HTL thickness } \\
/ \mathrm{nm}\end{array}$ & Process & $\begin{array}{c}j_{\mathrm{sc}} / \mathrm{mA} \\
\mathrm{cm}^{-2}\end{array}$ & $\begin{array}{c}V_{\mathrm{oc}} / \\
\mathrm{mV}\end{array}$ & $\begin{array}{c}\mathrm{FF} / \\
\%\end{array}$ & $\begin{array}{c}\mathrm{PCE} / \\
\%\end{array}$ & $\begin{array}{c}\text { Selectivity } \\
\%\end{array}$ \\
\hline PEDOT:PSS & 30 & standard & 8.97 & 611 & 62 & 3.39 & 95.0 \\
\hline $\mathrm{NiO}$ & 30 & $\mathrm{UVO} / \mathrm{AT}$ & 0.42 & 260 & 19 & 0.02 & - \\
$\mathrm{NiO}$ & 30 & $\mathrm{AT} / \mathrm{UVO}$ & 8.06 & 630 & 67 & 3.44 & 99.6 \\
$\mathrm{NiO}$ & 50 & $\begin{array}{c}\text { AT/UVO } \\
\text { as- } \\
\mathrm{NiO}\end{array}$ & 6.58 & 620 & 47 & 1.92 & 85.0 \\
& 30 & 0.20 & 258 & 23 & 0.01 & - \\
& & & & & & &
\end{tabular}




\section{References}

[1] F.C. Krebs, S.A. Gevorgyan, B. Gholamkhass, S. Holdcroft, C. Schlenker, M.E. Thompson, B.C. Thompson, D. Olson, D.S. Ginley, S.E. Shaheen, H.N. Alshareef, J.W. Murphy, W.J. Youngblood, N.C. Heston, J.R. Reynolds, S.J. Jia, D. Laird, S.M. Tuladhar, J.G.A. Dane, P. Atienzar, J. Nelson, J.M. Kroon, M.M. Wienk, R.A.J. Janssen, K. Tvingstedt, F.L. Zhang, M. Andersson, O. Inganas, M. Lira-Cantu, R. de Bettignies, S. Guillerez, T. Aernouts, D. Cheyns, L. Lutsen, B. Zimmermann, U. Wurfel, M. Niggemann, H.F. Schleiermacher, P. Liska, M. Gratzel, P. Lianos, E.A. Katz, W. Lohwasser, B. Jannon, A round robin study of flexible large-area roll-to-roll processed polymer solar cell modules, Sol. Energy Mater. Sol. Cells, 93 (2009) 1968-1977.

[2] F.C. Krebs, Fabrication and processing of polymer solar cells: A review of printing and coating techniques, Sol. Energy Mater. Sol. Cells, 93 (2009) 394-412.

[3] M.C. Scharber, D. Mühlbacher, M. Koppe, P. Denk, C. Waldauf, A.J. Heeger, C.J. Brabec, Design Rules for Donors in Bulk-Heterojunction Solar Cells-Towards 10\% Energy-Conversion Efficiency, Advanced Materials, 18 (2006) 789-794.

[4] Y. Sun, C.J. Takacs, S.R. Cowan, J.H. Seo, X. Gong, A. Roy, A.J. Heeger, Efficient, Air-Stable Bulk Heterojunction Polymer Solar Cells Using MoOx as the Anode Interfacial Layer, Advanced Materials (Weinheim, Germany), 23 (2011) 2226-2230.

[5] S. Chen, C.E. Small, C.M. Amb, J. Subbiah, T.H. Lai, S.W. Tsang, J.R. Manders, J.R. Reynolds, F. So, Inverted Polymer Solar Cells with Reduced Interface Recombination, Adv. Energy Mater., 2 (2012) 1333-1337.

[6] W. Chen, M.P. Nikiforov, S.B. Darling, Morphology characterization in organic and hybrid solar cells, Energy Environ. Sci., 5 (2012) 8045-8074.

[7] L. Dou, J. You, J. Yang, C.-C. Chen, Y. He, S. Murase, T. Moriarty, K. Emery, G. Li, Y. Yang, Tandem polymer solar cells featuring a spectrally matched low-bandgap polymer, Nat Photon, 6 (2012) 180-185.

[8] G. Greczynski, T. Kugler, M. Keil, W. Osikowicz, M. Fahlman, W.R. Salaneck, Photoelectron spectroscopy of thin films of PEDOT-PSS conjugated polymer blend: a mini-review and some new results, J. Electron Spectrosc. Relat. Phenom., 121 (2001) 1-17.

[9] K.X. Steirer, J.P. Chesin, N.E. Widjonarko, J.J. Berry, A. Miedaner, D.S. Ginley, D.C. Olson, Solution deposited NiO thin-films as hole transport layers in organic photovoltaics, Org. Electron., 11 (2010) 1414-1418. 
[10] S. Schubert, M. Hermenau, J. Meiss, L. Müller-Meskamp, K. Leo, Oxide Sandwiched Metal Thin-Film Electrodes for Long-Term Stable Organic Solar Cells, Advanced Functional Materials, 22 (2012) 4993-4999.

[11] J. Meyer, S. Hamwi, M. Kroger, W. Kowalsky, T. Riedl, A. Kahn, Transition Metal Oxides for Organic Electronics: Energetics, Device Physics and Applications, Advanced Materials, 24 (2012) 5408-5427.

[12] H.-Q. Wang, N. Li, N.S. Guldal, C.J. Brabec, Nanocrystal V2O5 thin film as holeextraction layer in normal architecture organic solar cells, Org. Electron., 13 (2012) 30143021 .

[13] E.L. Ratcliff, B. Zacher, N.R. Armstrong, Selective Inter layers and Contacts in Organic Photovoltaic Cells, J. Phys. Chem. Lett., 2 (2011) 1337-1350.

[14] M.D. Irwin, J.D. Servaites, D.B. Buchholz, B.J. Leever, J. Liu, J.D. Emery, M. Zhang, J.H. Song, M.F. Durstock, A.J. Freeman, M.J. Bedzyk, M.C. Hersam, R.P.H. Chang, M.A. Ratner, T.J. Marks, Structural and Electrical Functionality of NiO Interfacial Films in Bulk Heterojunction Organic Solar Cells, Chem. Mat., 23 (2011) 2218-2226.

[15] H. Yang, C. Gong, G.H. Guai, C.M. Li, Organic solar cells employing electrodeposited nickel oxide nanostructures

as the anode buffer layer, Sol. Energy Mater. Sol. Cells, 101 (2012) 256-261.

[16] E. Azaceta, S. Chavhan, P. Rossi, M. Paderi, S. Fantini, M. Ungureanu, O. Miguel, H.J. Grande, R. Tena-Zaera, NiO cathodic electrochemical deposition from an aprotic ionic liquid: Building metal oxide n-p heterojunctions, Electrochimica Acta, 71 (2012) 39-43.

[17] K.X. Steirer, P.F. Ndione, N.E. Widjonarko, M.T. Lloyd, J. Meyer, E.L. Ratcliff, A. Kahn, N.R. Armstrong, C.J. Curtis, D.S. Ginley, J.J. Berry, D.C. Olson, Enhanced Efficiency in Plastic Solar Cells via Energy Matched Solution Processed NiOx Interlayers, Adv. Energy Mater., 1 (2011) 813-820.

[18] E.L. Ratcliff, J. Meyer, K.X. Steirer, A. Garcia, J.J. Berry, D.S. Ginley, D.C. Olson, A. Kahn, N.R. Armstrong, Evidence for near-Surface NiOOH Species in SolutionProcessed NiOx Selective Interlayer Materials: Impact on Energetics and the Performance of Polymer Bulk Heterojunction Photovoltaics, Chem. Mat., 23 (2011) 4988-5000.

[19] F. Lin, D. Nordlund, T.-C. Weng, R.G. Moore, D.T. Gillaspie, A.C. Dillon, R.M. Richards, C. Engtrakul, Hole Doping in Al-Containing Nickel Oxide Materials To Improve Electrochromic Performance, ACS Materials \& Interfaces, 5 (2013) 301-309. 
[20] A. Guerrero, B. Dörling, T. Ripolles-Sanchis, M. Aghamohammadi, E. Barrena, M. Campoy-Quiles, G. Garcia-Belmonte, Interplay between Fullerene Surface Coverage and Contact Selectivity of Cathode Interfaces in Organic Solar Cells, ACS Nano, 7 (2013) $4637-4646$.

[21] G. Garcia-Belmonte, A. Guerrero, J. Bisquert, Elucidating Operating Modes of BulkHeterojunction Solar Cells from Impedance Spectroscopy Analysis, J. Phys. Chem. Lett., 4 (2013) 877-886.

[22] A. Guerrero, L.F. Marchesi, P.P. Boix, J. Bisquert, G. Garcia-Belmonte, Recombination in Organic Bulk Heterojunction Solar Cells: Small Dependence of Interfacial Charge Transfer Kinetics on Fullerene Affinity, J. Phys. Chem. Lett., 3 (2012) 1386-1392.

[23] T. Ripolles-Sanchis, A. Guerrero, J. Bisquert, G. Garcia-Belmonte, DiffusionRecombination Determines Collected Current and Voltage in Polymer:Fullerene Solar Cells, J. Phys. Chem. C, 116 (2012) 16925-16933.

[24] A. Guerrero, L.F. Marchesi, P.P. Boix, S. Ruiz-Raga, T. Ripolles-Sanchis, G. GarciaBelmonte, J. Bisquert, How the Charge-Neutrality Level of Interface States Controls Energy Level Alignment in Cathode Contacts of Organic Bulk-Heterojunction Solar Cells, ACS Nano, 6 (2012) 3453-3460.

[25] E. Azaceta, N.T. Tuyena, D.F. Pickup, C. Rogero, E. Ortega, O. Miguel, H.-J. Grande, R. Tena-Zaera, One-step wet chemical deposition of $\mathrm{NiO}$ from the electrochemical reduction of nitrates in ionic liquid based electrolytes, Electrochimica Acta, 96 (2013) 261267. 